\title{
Giving Each Person Her Due: Taurek Cases and Non-Comparative Justice
}

\author{
Alan Thomas
}

Accepted: 12 February 2012 / Published online: 29 March 2012

C The Author(s) 2012. This article is published with open access at Springerlink.com

\begin{abstract}
Taurek cases focus a choice between two views of permissible action, Can Save One and Must Save Many. It is argued that Taurek cases do illustrate the rationale for Can Save One, but existing views do not highlight the fact that this is because they are examples of claims grounded on non-comparative justice. To act to save the many solely because they form a group is to discriminate against the one for an irrelevant reason. That is a canonical form of non-comparative injustice. The error lies in taking a contingency of some presentations of some Taurek cases, namely, that they involve distribution, to introduce the claims of comparative as opposed to non-comparative justice. But cases of non-comparative justice can, contingently, also involve distribution. In order to settle which form of justice applies it is necessary to examine the nature of the distribution involved and the nature of "classes" to which individuals can be assigned.
\end{abstract}

Keywords Taurek $\cdot$ Numbers scepticism $\cdot$ Particularism

In one of the most famous papers in normative ethics John Taurek argued that in certain kinds of dilemmatic situation, where a rescuer can save one person, or a group of five people, but not both, then the agent's reasons fail uniquely to determine a verdict (Taurek 1977). It is morally indifferent whether the rescuer saves the one or the many. Taurek further claimed that the rescuer ought to act fairly. ${ }^{1}$ He understood this as requiring the rescuer to distribute equal chances to be saved across all six people. Both claims, that of moral indifference, and the distribution of equal chances, led to Taurek's striking conclusion that the best decision procedure available to the agent was the toss of an unbiased coin.

\footnotetext{
${ }^{1}$ In those cases where saving the one is not directly motivated by permissible partiality alone; I am grateful to Ben Saunders for pressing me to emphasise this point.
}

A. Thomas $(\bowtie)$

Department of Philosophy, Tilburg University, PO Box 90153, 5000LE Tilburg, The Netherlands

e-mail: a.thomas@uvt.nl 
Taurek reasoned that, given that common sense morality contains a principle of partiality, one could permissibly save the one if that principle applied. So the obligation to save as many lives as possible does not exhaust the content of common sense morality. ${ }^{2}$ Absent some special, contractual, obligation to the many the rescuer is not, therefore, unrestrictedly required to save them. (Such "contractual" obligations include the requirements attaching to institutional roles, such as that of lifeguard or firefighter.) Given that death is the limiting case of harm, the outcome proposed is just as bad for the one as it is for each of the five, so it is permissible to save the one. In the substantial literature on Taurek it is customary to interpret his claim as the defence of a principle: the principle is usually called Can Save One as opposed to its opposite, Must Save Many. ${ }^{3}$

In this literature no one has proposed defending Taurek's basic intuition that it is permissible to save the one as opposed to the many by removing a mistake in his approach to fairness. I will argue that, by doing so, his more controversial claims fall away, leaving his conclusion untouched. I will follow Joel Feinberg in drawing a distinction between comparative and non-comparative justice. I will argue that the kind of fairness involved in Taurek cases is not, as Taurek seemed to assume, comparative (Feinberg 1974). This gives a simpler and more intuitive argument from truistic premises to Taurek's conclusion that it is permissible to save the one. Notably, it omits his controversial coin toss. That may be Taurek's most striking claim, but it rests on a mistaken view of fairness, and has exposed his core argument to many misguided objections.

Throughout this paper my approach will be compatible with meta-ethical particularism: it is not my aim here to defend a verdictive conclusion. ${ }^{4}$ This will prove important to the assessment of Kamm's and Scanlon's critiques of Taurek as both depend on a prior assumption of the truth of both moral generalism and reasons atomism. My aim is better characterized as identifying a certain kind of evidential consideration; a reason that is normally wrong making. This makes my position compatible with the "mixed" solutions, that take numbers sometimes to count in Taurek cases, of Sanders, Munoz-Dardé, Lawlor and Peterson (Sanders 1988; Munoz-Dardé 2005; Lawlor 2006; Peterson 2010). I am not opposed to the idea that the moral permissibility of saving the one could be overridden by a disaster clause and that it would be wrong overall to save the one at the cost of a million innocent lives. But I do take myself to have established that, even in that case, the course of action is regrettable. That is because there is a reason to have acted otherwise grounded on the claim in non-comparative justice of the one that we have sacrificed for the lives of the million innocent people. There is a puzzling moral remainder that the truth of Must Save Many, taken as the sole principle governing this case, would fail to explain.

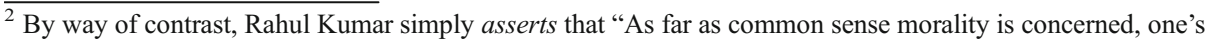
duty as a rescuer, under the circumstances, is a straightforward matter: one ought to save the greater number". (Kumar 2001, p. 165) But he does not say why he thinks the principle is true nor why he thinks it is a "straightforward" part of commonsense morality.

${ }^{3}$ I take this terminology from Doggett (2009) but I have altered "Can Save Few" to "Can Save One". One interesting change in the Taurek literature is that his paper is interpreted as expressing a generalized "numbers scepticism". Needless to say, the sleight of hand involved in calling Taurek's view a form of "scepticism" - a denial of a claim in common sense morality — ought not to be allowed to pass unchallenged. It is the claim that common sense morality contains a principle corresponding to Must Save Many that ought to be the target of our scepticism.

${ }^{4}$ An interesting contrast is with Munoz-Dardé's (2005) ambition to identify in Taurek cases "a conclusive reason from which we can derive a duty", p. 210. Contrast her definition of a "conclusive reason", (ibid., p. 211) with Dancy's discussion of a "decisive principle" in his (2004), pp. 17-25.
} 


\section{Taurek Cases and Non/Comparative Justice}

Suppose that the contingencies of the situation put you, the unhappy rescuer, in a situation where you can save one person, or five people, but not all six. Does common sense morality contain an obligation that you Must Save Many? Or is Taurek correct to argue that common sense morality permits actions that fall under the principle Can Save One?

My main claim is that while Taurek's examples involve a distribution, this fact alone does not settle whether they involve comparative or non-comparative justice, as distinguished by Joel Feinberg (Feinberg 1974). In any case of comparative justice, when it comes to the distribution of contingently limited benefits and burdens to individuals, the treatment of any individual is essentially relational. It is related to the treatment of the others in that class. A corollary is that any assignment of a good must always consider how much of that good is left over for the others in that class, because it is essential that all claims are treated comparatively. This is what it is to respect claims of this kind.

In the contrasting case of non-comparative justice, giving a person her due is determined solely by considering that person taken alone. We do not need to know what is due to other people in order to know what is due to that person taken in isolation from any relevant class of individuals similarly placed. Meeting claims in non-comparative justice is essentially nonrelational and this will prove crucial to much of what follows. The fact that other individuals are similarly placed to the person whose claim is under consideration is an irrelevant contingency. Thus comparative justice requires equality of treatment across a relevant class whereas noncomparative justice does not. In the noncomparative case, measurement by desert or by what Feinberg calls an "objective standard" applies to the individual taken alone. It suffices to determine what she is due. That is what it is to respect claims of this different, non-comparative, kind. ${ }^{5}$

My main thesis is that Taurek cases do involve fair treatment, but not in the sense of comparative justice. The relevant notion of fairness is that involved in non-comparative justice. That allows an explanation of why a distinctive kind of wrong is done to a person if one saves the many, rather than the single person, simply because of the contingency that she is not a member of a group. A key point for applying Feinberg's distinction to Taurek cases is that even cases of non-comparative justice can still involve distribution as a contingent aspect of particular situations. An upshot of such an example may be that:

We may decide, on the basis of information about other parties, to withhold from him his due; but no new data can upset our judgement about what is his due. (Feinberg 1974, p.300, emphasis added)

In this kind of scenario we have determined what each person is due. ${ }^{6}$ However, we may, owing to contingent features of the case, fail to provide it. This is a distinctive form of failure to meet a claim in justice applicable to non-comparative cases.

\footnotetext{
${ }^{5}$ This seems to me a more helpful way to bring considerations of justice to bear on Taurek cases than to imply, as Munoz-Dardé's (2005) discussion implies, that we have two different subject matters here, namely, social policy versus principles governing relations between individuals. There are interesting parallels between the view defended here and some of Munoz-Dardé's claims in her paper, but it seems to me that we can speak of both comparative and non-comparative justice in both individual morality (as Scanlon conceives of the narrow domain of "what we owe to each other") and in the case of political applications of the idea of justice. It may well be that all plausible conceptions of political justice are comparative, but that is a substantive issue not determined by the domain of application of any candidate principle.

${ }^{6}$ Compare Jerry Cohen's remark in Rescuing Justice and Equality, "But if, as some of my critics insist, I simply must say what I think justice is, in general terms, then I offer, for those who will be content with it, the ancient dictum that justice is giving each person her due", (Cohen 2008, p. 7).
} 
Now, in a Taurek case, someone is going to have their claim in justice acknowledged, but not met. There is, however, an asymmetry between the case of the one and the many. Consider the singleton: if Must Save Many is true, then the contingent fact that she is alone is the ground for not meeting her claim in non-comparative justice. She is being denied her due, in the noncomparative sense, solely because of the irrelevant fact that she is not part of a group. Therefore, if we do not save her solely because she is not part of a group then we have discriminated against her for an irrelevant reason. She has a reasonable complaint, based on non-comparative justice, that we have acted unjustly towards her. Before going on to explain why the case of the group is different from the case of the singleton, let me explain what I mean here by discrimination.

Why is it discrimination against the one when the five are saved, but not vice versa? To establish an instance of discrimination we need a comparison class and a principle of selection from that class that generates a reason for that selection. The relevant comparison class is composed of the six people who are candidates to be saved. There are two putative selection principles: Can Save One and Must Save Many. It is in the light of the presupposed truth of Must Save Many that I argue that to save the group is to discriminate against the one on the basis of an irrelevant reason. She is selected for different treatment from the rest of the comparison class by that principle for an irrelevant reason, namely, that she is the singleton. This introduces a distinctive kind of wrong making consideration that grounds a reasonable complaint from the singleton that she has been unjustly treated.

To re-iterate: given the non-relational nature of claims in non-comparative justice, what the single person is owed does not depend on the fact that others are similarly placed to her, but simply happen to form a group. The irreconcilable conflict here is between the nature of claims in non-comparative justice and the reason generated by the principle Must Save Many to justify discriminating against the singleton. Given that her claim is essentially non-comparative, whether she is in a group or not can never be relevant to meeting it. So the issue, then, is not simply that she is picked out arbitrarily: sometimes arbitrariness can be fair. The issue is the irrelevance of the cited reason given the nature of non-comparative claims.

Why is the situation of the group different? Because, by contrast, the principle Can Save One acknowledges that all six candidates in the comparison class have valid claims in non-comparative justice and, further, no one acts wrongly towards any of the six candidates to be saved in the light of that principle when they save the one. (This latter point uses a distinction between failure to meet an acknowledged claim, and acting wrongly, that I will explain further below.)

\section{Why Are Taurek Cases Instances of Non-comparative Justice?}

Why do I believe that it is more appropriate to classify Taurek cases as instances of noncomparative rather than comparative justice? For three main reasons: the distinction between public agencies and private individuals, the absence of a plausible object to be distributed in a comparative way, and the artificiality of the class under consideration.

I will discuss the first two points together as they are closely connected. What is supposed to be distributed in a Taurek case? Taurek's proposal is that the factor distributed is "chances to be saved". This has always struck me as a very implausible claim. When we think about justice in a comparative way, it is natural to think of some public body engaged in the distribution of scarce goods, such as welfare, or some other distribuendum selected from a list of primary goods. The perspective of a public agency is very different from the perspective of a rescuer in a Taurek case. Why should the latter so much as conceive of herself as being in the distribution business? Of course, she wants to be fair to all parties. My view is that this means being noncomparatively fair and that is exhausted by acknowledging that each of the six candidates to 
be saved is owed rescue. If one takes the alternative, comparative view of justice, what is the distribuendum that the rescuer is supposed to be distributing?

The putative answer is "equal chances to be saved". But consider how unusual a candidate this is as a "good" to be distributed. Public agencies do regulate airline safety, place lifebelts at the sea front, and station firehouses proportionately to the population that they cover. But it seems to me a misdescription of what these public agencies do to say that they distribute equal chances to be saved. I think the more accurate description is that they distribute equal protection against risk. They do so, not with the overall aim of equalizing chances to be saved, but with saving everyone who needs to be saved. We are, after all, only in the business of saving people when our protections from risk have failed. At that point we aim not to give them equal chances to be saved but to save them, simpliciter. If we collectively determine a distributive scheme for protecting everyone equally from risk, then we aim at equality of outcome where everyone is, in fact, saved, but in Taurek cases that is not going to happen. Whatever we do, someone is going to die. Why are we distributing equal chances to be saved amongst a group of people at least one of whom will not be saved? The reason that we collectively distribute protections against risk, not chances to be saved, is that no sensible distributive scheme can guarantee that. This is for the reason that contingent and unpredictable factors intervene between our scheme of equal protection and the outcome in which a person needs to be saved. By the time the issue of being saved arises, why is a rescuer, acting in a private capacity, in the business of fairly distributing chances to be saved? ${ }^{7}$

Taurek might reply: the demand stems not from fairness, but from an agent-centred requirement to act fairly towards all six people. (See also Lawlor 2006) We want to justify our actions to all parties and that requires a principle of fairness. Only the fair distribution of equal chances to be saved meets this requirement. But that is not true: the personal virtue of justice can express non-comparative as opposed to comparative justice. To act noncomparatively justly to all six is to act fairly and in a way that can be justified to all six candidates to be saved, even to the five who are not saved.

This point is relevant to another argument that brings considerations of fairness to bear on Taurek cases, that of Gerald Lang (Lang 2005). Lang contrasts Taurek's equalizing of chances to be saved (which Lang calls "selection fairness") with what he calls "outcome fairness". The former partly expresses our concern to treat everyone equally, but Lang argues that this concern must be supplemented by the latter, or there is more selection unfairness to the group, if it is not saved, compared to saving the one. Lang's proposal brings out clearly the difference between the role of a distributive scheme of protection and the equalization of outcomes. If the former fails to deliver the latter, why is it the job of a rescuer in Taurek cases to see to it the vector of both represents a fair distribution in the comparative sense? ${ }^{8}$

\footnotetext{
${ }^{7}$ This is quite different from the question: are you, as a coastguard, police officer or pool lifesaver under an institutional obligation that takes the form Must Save Many?

${ }^{8}$ I can only note here, and not pursue, the broader connection with how we conceive of egalitarianism and its goals. In a well-known paper, Elizabeth Anderson complained that broadly Kantian luck-egalitarianism distorted the nature of our concern for equality. (Anderson 1999) One of her representative targets was Van Parijs's proposal for a "bride auction" when a group of women have a right to be married, but the number of eligible partners is scarce. Each woman is given a tradable right and has to bid for a marriage partner, thus channeling compensatory resources to the "unlucky in love" who receive financial compensation. Anderson complains that this does not merely get the scope of (public, comparative) justice wrong; it also misrepresents the point of our interest in equality. This luck-neutralising impulse unifies consequentialist and Kantian alike, reflecting the underlying impulse of the Morality System for a luck free account of the moral. There is a direct connection between these ideas and the proposal that Taurek cases distribute (in a comparative way) equal chances to be saved. The singleton, when she is not rescued either by the consequentialist or the contractualist, dies clutching her fair distributive share and knowing that she had received "equal consideration" and had thus been "compensated" for her bad luck in being alone. See also footnote 14 .
} 
What other candidates might there be for a distribuendum in Taurek cases if they involve comparative justice? Suppose, instead, that one argues that time and resources are to be distributed comparatively in Taurek cases? This is a trivialization of the issue: now every single action that one performs is, in that sense, a distribution of something in way that trivializes this claim.

Similar problems beset identification of the class, or group, in a Taurek case. Cases of comparative justice make the distribution of a good essentially relational: as I distribute to each member of a class I must bear in mind the claims of all the others in the relevant class. The key term here is "class": there must be some identifying criterion or mark that defines a class. A class, here, is not a mere collection. But in Taurek cases the relevant group is merely a collection. It is mere happenstance that, if I can take my boat to save one person from an island or take it to another to save five, that the five form any kind of group. It is the mere contingencies of the situation that dictate that there is a "group" here at all. There is no principle governing assignment to the group. Even those who are opposed to Taurek's conclusion concede the point as no one claims that the members of the group gain any additional reason to be saved qua group. There is no group claim over and above the claim of each of the several persons who make up the group. ${ }^{9}$ That fact casts further doubt upon the initial diagnosis that this is a case of comparative justice in the first place. I believe that it is not, both because there is nothing to be distributed in Taurek cases other than the trivial factor of the rescuer's time and resources, and because of the arbitrary nature of the identified group. ${ }^{10}$

By contrast, compare meeting claims in comparative justice, such as the distribution of primary goods in a fair way. Here there is a factor to be distributed and an identifiable class picked out by an independently specifiable criterion, namely, citizens of the relevant political community. A civil servant administering a welfare programme who examines each individual case, decides each on its non-comparative merits, and distributes resources such that the whole programme is bankrupt after the first thousand claimants have been paid, has failed to understand the nature of demands in comparative justice. That is because she has failed to grasp the relevance of the defined class of beneficiaries. Taurek cases are, then, importantly different in two respects from this kind of case. There is no distribuendum, and the group involved is wholly arbitrary and artificial and so not a defined class. Add the fact that a rescuer in a Taurek case does not have to see herself as acting in lieu of some public body, distributing some contingently limited good, and I think it is far more plausible to argue that Taurek cases involve non-comparative justice than comparative justice. $^{11}$

\footnotetext{
${ }^{9}$ Mike Otsuka claimed that the contractualist arguments of Kamm and Scanlon illegitimately smuggled in a group claim of this kind, but the objection I have raised to their view, drawing on Tyler Doggett's work, has not pursued that line of criticism. (Otsuka 2000; Doggett 2009, forthcoming) I think Kumar (2001) offers an effective response to that point, but falls foul of Doggett's criticism of the implicit reasons atomism in the Kamm-Scanlon argument.

${ }^{10}$ Martin Petersen has suggested to me that, by your action as a rescuer, you create the relevant sense of a group or class. But I do not think that will work, as the fact that you can save one person or a group is supposed to be an input into deliberation, not a consequence of the action that terminates it.

${ }^{11}$ In the interests of clarity, let me note that there is one sense in which there is a comparison in a Taurek case: there is a decision between two actions (and, by default, inaction) and in that sense the rescuer is comparing two acts and their outcomes. This comparison, however, is over two outcomes in which the demands of noncomparative justice will, in at least one case, not be met. I am grateful to Brad Hooker for pressing me to clarify this point.
} 


\section{The Priority of Non-comparative Justice}

Taurek simply assumed that his examples involved comparative justice whereby we distribute equal chances to be saved. In my view even if the singleton wins the coin toss, her claim to be saved has been misrepresented if it is interpreted as a fair share of some distributive resource. So I am committed to seeing non-comparative claims as prior to comparative ones and that marks an interesting difference between my view and that of John Broome's (1990). He believes that fairness requires that if someone gets anything, then everyone should get something; in other words, fairness is a comparative idea through and through. ${ }^{12}$ In the course of defending Taurek's decision procedure from Kamm's criticism of it, he argues that:

Equal chances provide a surrogate equality of satisfaction, and so a degree of fairness. It is not true equality of satisfaction, and therefore would not (be) completely fair, but it is fair to some degree. Saving no one would be the fairest thing to do; tossing a coin the next fairest. (Broome 1998, p. 956)

The difference between us is that while Broome insists, correctly in my view, that all six candidates to be saved are owed saving, we then differ over whether these are claims in comparative or non-comparative justice. Because Broome assumes it is the former, he then formulates the requirements of fairness as he does. But I am arguing there is another way to meet the demands of fairness once they are disambiguated into comparative and noncomparative demands.

I think there is another reason why this is preferable to Broome's approach: because his focus is solely distributive in the comparative sense, he thinks not only that it is fair if you do not act at all but that this would be the fairest outcome in a Taurek case. The wrongness of not acting at all, he thinks, is explained by a distinct set of considerations about value. Indeed, Broome takes the fact that not rescuing anyone would be wrong, but not unfair, as evidence that fairness cannot be prior to questions of goodness. (Broome 1998, p. 956) This does not follow, however, if one argues, as I have, that Taurek cases involve noncomparative justice. If this is the correct description of what such cases involve then failing to meet what is due to any given individual is a defect in justice. This restores the priority of justice to questions of value; ${ }^{13}$ so, fortunately, I do not in this paper have to enter the separate discussion of Taurek's "no worse claim" about the evaluation of outcomes (Lübbe 2008). This is important, as it seems to me that Broome's vector view, which takes the evaluation of outcomes to tip the balance against fairness taken alone, depends on denying this priority.

The priority of non-comparative over comparative justice also allows one to reject the proposal to replace the coin toss with a lottery. Weighted lotteries are proposed by the kind of vector view of considerations of fairness and evaluation that thinks it is wrong that the singleton has as much chance of being rescued as the group. By contrast, equal chance lotteries have been proposed to replace Taurek's coin toss so as to smuggle in the claims of a group into a contractualist framework de facto, as Jens Timmerman puts it, not de jure. What is my objection to these specific proposals? (Timmerman 2004)

Once again, that these are methods of distribution appropriate to comparative justice so, for that very reason, inappropriate for Taurek cases. But considering these proposals allows

\footnotetext{
$\overline{12}$ I owe this useful form of words to Tyler Doggett.

13 John T. Sanders's complained that whatever principle Taurek took himself to be defending, it was a further error to make it lexically prior to all other principles and/or automatically overriding of those principles. (Sanders 1988) But when it comes to the priority of non-comparative to comparative fairness it seems to me Taurek was right to argue for such priority - even if lexical priority is too strong a claim.
} 
me to clarify one aspect of my argument: I have conceded that in some cases, arbitrariness is compatible with fairness. For that reason I have referred only to discrimination for the wrong reasons and not of "arbitrary" discrimination. The result of a lottery can be fair and the singleton might hold the winning ticket, just as she might have won the coin toss. (The result of the lottery will trump a principle such as Must Save Many. ${ }^{14}$ So why ought the singleton to object to these proposals to operationalise her fair chances via any kind of lottery? On my now familiar grounds that giving her a lottery ticket makes whether or not her claim in noncomparative justice is met dependent on the irrelevant fact that she is the member of a group, this time, the group of all six candidates to be saved. The singleton should decline the lottery ticket on the grounds that it makes whether or not her claim is met dependent on whether or not the claims of others are met that imports an irrelevant, distributive perspective to an issue of non-comparative justice. This is clearest in the case of weighted lotteries, where an evaluative principle is responsible for generating the pressure to weight the lottery against the singleton thus illustrating why any lottery proposal is an instance of comparative justice. As for the individualist lottery, that proposal collapses under its own weight: the idea is that in a simple one person versus two person case, if one of the pair holds the winning ticket then, in saving him, "the rescuer then incurs an obligation to save (the third person)". ${ }^{15}$ (Timmerman 2004, p. 110).

In a truly Scholastic piece of reasoning, the rescuer claims the he goes to the location where the group are located only to save the winner, and it is just good luck for the group that the rescuer can save them, too. But the dilemma for this view is this: either the rescuer has no obligation to save anyone other than the winner or the rescuer does have an obligation to take the remainder of the group if he takes the lottery winner. ${ }^{16}$ On the first horn of this dilemma we simply have grounds for saving the one and leaving the rest of the group. On the second horn of the dilemma, the problem is that the obligation to take the group if you take any of its members is based on the wrongness of discrimination. But that is precisely the reason I have cited to ground the permissibility of saving the one. Either way, the individualist lottery justifies only

\footnotetext{
${ }^{14}$ Timmerman introduces his version of the individualist lottery proposal by noting that, otherwise, the singleton can object "that he never stood a chance" if equal chances to be saved are distributed in any kind of aggregationist framework (Timmerman 2004, p. 203)

${ }^{15}$ Unfortunately, as Kathryn Brown pointed out to me, it is not clear that this maneuver stops the equal chances of the individualist lottery in fact constituting a weighted lottery, as members of the group buy five chances with their one ticket. Frances Kamm at one point considered permitting this pooling, on the grounds that equal consideration demanded only the (comparative) distribution of equal baseline chances to be saved and then the members of the group are simply lucky in being able to pool their shares. (Kamm 1993, p.131) But John Broome was surely right to object to this proposal that: "There is no distinction between baseline chances and final chances in this case. If you adopt the procedure of proportional chances, you are simply making the chances of the six people unequal; you are giving a five-sixths chances to five of them and a one sixth chance to one. This cannot possibly be justified by appealing to the fairness of equal chances". (Broome 1998, p. 960) I would add that no-one in this discussion proposes making equal chances to be saved tradable in a way analogous to the Van Parijs Bride Lottery (see footnote 7, above). All six candidates would be able to bid for rescue, thus removing the exclusion of the singleton from the ability to pool her chances. Indeed, if the singleton is a billionaire and the five are of ordinary means, she would win the auction. I mention this option not only because the very idea of trading in chances to be saved is morally repugnant to everyone in this discussion, but to reinforce Broome's point that Kamm's proposal is basically libertarian (although he does not use that word) (Broome 1998, p. 960).

${ }^{16}$ And, as Kathryn Brown further pointed out to me, noting a third option reduces the whole lottery proposal to absurdity. The rescuer, having saved the winning ticket holder alone, has no more reason to save any of the other four in the group than he has to save the single person stranded alone. This reflects the fact that otherwise the singleton can complain that after an unrelated person won on another island, she "never stood a chance" vis-à-vis the lucky beneficiaries on the other island who just happened to be in a group. But Timmerman introduced his lottery precisely to address that concern (see footnote 13).
} 
saving the one, contrary to its ambition to find a contractualist route to denying Taurek's conclusion. I will now turn to contractualism's problems with Taurek.

\section{Scanlon and Kamm's Flawed Critique of Taurek}

If my diagnosis of what is involved in Taurek cases is correct, then Taurek's distributive and hence comparative focus has sent many of his critics down a false path. Taurek introduces his case via Philippa Foot's famous example in which a doctor can save either one patient or five patients because of the contingent limitations in the supply of a life saving drug. (Foot 1967) (One patient needs all of the available supply while each of the five needs only a fifth.) The problem from my point of view is that if Taurek introduces his distinctive thesis using such an example he seems immediately to imply that this is a case of comparative justice solely because the case is one of distribution. ${ }^{17}$ But as Feinberg points out, that does not follow: a distributive case might, nonetheless, involve non-comparative justice.

Clearly, from my perspective, things go from bad to worse when Taurek introduces his notorious claim that in morally indifferent cases one ought to toss a coin to decide what to do. This follows directly from his claim that acting fairly here involves the principle of distributing equal chances to be saved. That idea has proved important to by far the most important of the criticisms of Taurek, namely, that developed by Frances Myrna Kamm and Thomas Scanlon Jr. (Scanlon 1999; Kamm 1993, 2007). (They are independently interesting as they are developed by two non-consequentialists.) Scanlon explains the basic motivation for their line of argument as follows:

(The Taurek view) would permit someone, faced with the choice between saving one stranger from death and saving two other strangers from the same fate, to save only the one. In such a case, either member of the larger group might complain that this principle did not take account of the value of saving his life, since it permits the agent to decide what to do in the very same way that it would have permitted had he not been present at all, and there was only one person in each group. The fate of the single person is obviously being given positive weight, he might argue, since if that person were not threatened then the agent would have been required to save the two. And the fact that there is one other person who can be saved if and only if the first person is not saved is being given positive weight to balance the value of saving the one. The presence of the additional person, however, makes no difference to what the agent is required to do or to how she is required to go about deciding what to do. This is unacceptable, the person might argue, since his life should be given the same moral significance as anyone else's in this situation. (Scanlon 1999, p. 232)

The basic idea, then, is that when we decide in Taurek cases we must decide in the light of some principle of fairness. That principle of fairness is to guide us in the distribution of some distribuendum, namely, "chances to be saved". Those chances must be equalized across all involved parties. Make those assumptions and the tiebreaker argument goes through, refuting Taurek's position but without aggregating claims. Clearly I think this critique can be avoided if there are further considerations in Taurek cases grounded on non-comparative justice. I also believe that the argument, as it is presented, fails because of its implicit reasons atomism.

\footnotetext{
${ }^{17}$ Indeed, Taurek opens his discussion with these words "We have resources for bestowing benefits and for preventing harms. But there are limitations". (Taurek, p. 293) In other words, a distributive and hence comparative perspective seems built in to his argument from the start.
} 
I have already expressed my scepticism as to whether this is a case of comparative justice involving the distribution of chances to be saved. Tyler Doggett points out that a further issue raised by the Scanlon-Kamm argument is a methodological one about reasons. ${ }^{18}$ (Doggett 2009) An important role is played in Scanlon's argument by his reasons atomism. For him, all reasons figure in deliberation in the same way with a pre-determined weight. That assumption informs how we reason counterfactually about different possible scenarios. According to this atomistic methodology, what we do is "solve for" the contribution that the presence, or absence, of the weight attaching to a reason makes in each case. Adding and removing persons to each scenario is like placing weights on a weighing scale and assessing the result.

To simplify to the one, two and three person case: in the "one person" case the reason generated by the presence of one person needing assistance is "automatically decisive". Since there is only one reason, it automatically generates a verdict. Add a disjoined "two person" case where one can save A or B and the "scales" are now equally balanced. Scanlon's thought seems to be that if one now adds C to B to form a "single person versus a two person group" case, it is troubling that, on the "Can Save One" view, the scales still do not move. For both Scanlon and Kamm person $\mathrm{C}$ is not making a morally relevant difference to the situation and that is not fair.

The metaphor of "weight" here adds nothing to the argument and we need to understand it in non-metaphorical terms. There seem to be two points implicit in the Scanlon-Kamm argument: the first is that person $\mathrm{C}$ is not receiving appropriate moral consideration and that, more precisely, person $\mathrm{C}$ is denied an equal chance to be saved. The previous considerations suggest instead that the first claim is false and the second irrelevant. However, this is where the metaphor of weight is illegitimately doing its work: from the fact that adding person $\mathrm{C}$ to a counterfactual scenario does not change the "balance" of reasons Scanlon concludes that the presence of $\mathrm{C}$ is not making a difference to the outcome. However, Tyler Doggett has pointed out that defenders of Can Save One do not deny that adding person C makes a moral difference. ${ }^{19}$ I offer here an underlying rationale for Doggett's point. My explanation is that person $\mathrm{C}$ also has a legitimate claim in non-comparative justice. That suffices for her to be morally considered. But it is not true that Taurek cases require the fair distribution of equal chances to be saved because this is not a case of comparative justice requiring equal treatment across an identified class of people (in part, because there is no such "class").

Kamm and Scanlon seek to neutralize Taurek's method by using a particular model of balancing reasons where we go through claims seriatim: so the presence of A alone requires that A be saved; the presence of incompatible A or B means that it is indifferent which you do. But, at that point, the "balance of reasons" means that the reasons to save A or B now "cancel out" so in this exercise in moral arithmetic the arrival of third person C to join B now adds a decisive reason. ${ }^{20}$ The problem with this view, as Tyler Doggett notes (though not in

\footnotetext{
${ }^{18}$ As noted in the helpful discussion in Doggett (2009), pp. 6-13.

${ }^{19}$ While I am indebted to the careful arguments of Doggett (2009) there is an artificiality in his treating "the one" as the limiting case of "a group" in the course of his argument against Scanlon and Kamm that "A necessary condition for a view being fair... is that like persons make like differences to what is permitted.... Can Save Few meets this condition. If it is true, Alan, Bob and Christine do make like differences to what is permitted, viz., you are permitted to save each person and, if you save someone in his or her group, you are required to save everyone else in the group, too." pp. 2-3. This gives us fair treatment at the cost of treating one person as a group of one; focusing on non-comparative justice removes this artificiality and suggests a different way of generalizing to the large group/small group case.

${ }^{20}$ This "cancelling out" idea was a supplement to Kamm and Scanlon's argument suggested by Rahul Kumar, see Kumar (2001) p. 167. (Kumar uses the word "neutralizing".) He used it to reject Mike Otsuka's objection that the contractualist is tacitly working with a group claim; whatever the merits of this rebuttal, the same idea comes back in the subtle discussion of the issue in Timmerman (2004) section 4.
} 
these terms) is its incoherent combination of reasons atomism with reasons holism. If our choice is $\mathrm{A}$ or $\mathrm{B}$, then the reasons for saving either cancel each other out. But then the reason to save A plays a different role in the A or (B and C) case. A local reasons holism does its job and A "cancels" B so as to permit the overall verdict generated by the "decisive" presence of the reason generated by $\mathrm{C}$. However, Doggett points out that reasons only work this way in the $A$ or ( $B$ and $C$ ) case and do not work in the same way in the A or B case. That is because Scanlon does not argue that in that latter scenario A performs its "reasons cancelling" role: if it did then we would have no reason to act at all in that case. (Doggett, p. 8, see also Lang 2005) But you cannot be both a reasons atomist and a reasons holist in the same argument. ${ }^{21}$ Reasons cannot sometimes change their role in combination with other reasons, and sometimes not, with no further explanation of this difference.

Does it help that Kamm's argument goes beyond the metaphor of weight by adding an explanation of why the presence of person $\mathrm{C}$ is not making a moral difference? Kamm concludes from the fact that this is a distributive context that any principled solution to the problem will involve fairness. I think that is correct. She also concludes that the relevant principle will be one of comparative justice. I do not think that is correct because it overlooks the important differences between comparative and non-comparative justice. I have already argued that all the later refinements of Kamm's argument are misguided. We do not need to accept Taurek's and Kamm's characterization of the situation at all. From the fact that it involves a distribution, one cannot conclude that it is an instance of comparative justice.

Am I then committed to denying that in Taurek cases everyone has an equal chance to be saved? I need neither affirm nor deny this claim. I think it is simply inapplicable to this kind of case: that of a private individual, acting in a private capacity, with no prior contractual or institutional obligation to save the many. The more limited claim that I want to defend is that it is morally permissible to save either the one or the many. So, as a result, it is morally indifferent which you do. ${ }^{22}$ We ought to save everyone, and meet everyone's legitimate claim in non-comparative justice, but for contingent reasons we cannot. If we do not save the one solely because she is isolated then we will do her a particular kind of wrong distinctive of non-comparative justice. In comparison, while we will not be meeting the claims in noncomparative justice of each of the five we will not be treating them unjustly. (I will return to that claim below.) My argument stops there: Taurek's controversial "coin toss" proposal arises because he focuses on this distinct question: what is an appropriate decision procedure for morally indifferent claims that also equally distributes chances to be saved? That is a question I do not address in this paper. ${ }^{23}$

This leaves a more concessive line of argument available to me. Feinberg notes that there are few cases of exclusively comparative and non-comparative justice; most examples involve elements of both. So I can concede that a Taurek case might involve equal chances

\footnotetext{
${ }^{21}$ A separate line of argument against Scanlon, the charge that he begs the question by assuming the truth of Must Save Many throughout his "balancing" argument, is fruitfully pursued by both Munoz-Dardé (2005) pp. 215-216 and Peterson (2010).

${ }^{22}$ Given the further assumptions that you must do something (an assumption that only a libertarian would contest) and absent some further reason that trumps considerations of justice. (I am grateful to Ben Saunders for asking me to clarify this point.)

${ }^{23}$ Han van Wietmarschen pointed out to me that in an epistemic indifference case one can suspend belief while in a Taurek case all parties agree it would be wrong to do nothing (except those of a strongly libertarian persuasion). I simply note Anscombe's remark in the same paper that 'When I do action A for reasons R, it is not necessary or even usual for me to have any special reason for doing-action-A-rather-than-action-B, which may also be possible'. (Anscombe 1967, p. 17) I merely decided on my reasons, which is not to add another reason.
} 
to be saved provided it is also conceded that it also involves fairness in the non-comparative sense. My aim is to prove that both Can Save One and Must Save Many apply to this case, not the latter principle taken alone. Clearly, however, this kind of plural principle view will have to revise Must Save Many so that it takes the form of a weakened successor principle Can Save Many.

The current state of the dialectic is that even those sympathetic to Taurek, such as Tyler Doggett, think that "Can Save Few" taken alone is "lunatic"! ${ }^{4}$ The burden of proof is on me to show that there is a further consideration that Must Save Many, taken alone, fails to accommodate. I will have achieved this if Taurek cases involve both equal chances to be saved and further considerations grounded in non-comparative justice. If both principles apply I will have made a case for a plural principle position that balances the claim of Must Save Many (revised to become Can Save Many) and the claim of Can Save One. ${ }^{25}$

Furthermore, the foregoing account illuminates Taurek's method of pair-wise comparison in assessing claims. Each of the six people has a claim grounded in non-comparative justice even though, for contingent reasons, not everyone can be given her due. So the method of "balancing claims" by comparing the claim in non-comparative justice between the one and each of the five is an appropriate way of balancing non-comparative claims. Each is owed her due and in the same way. If it is morally indifferent whether you save the one or the five and you save the one, then each of the five has been denied her due (just as, in the reverse case, the one would have been denied what is due to her). Deploying the method of pair-wise comparison is, of course, entirely separate from the thesis that one can make a choice between morally indifferent claims by tossing a coin (or holding a weighted lottery).

\section{Wrongs in Non-comparative Justice}

A key element in the foregoing is that the nature of the complaints that the one, or each of the five, can bring if he or she is not saved differ in an important way. The claim in noncomparative justice is denied on the part of the one solely because she is not a group member. That is discrimination, one of the three canonical forms of non-comparative injustice. The five, by contrast, are not discriminated against if the rescuer saves the one. But has this lost an important feature of the case, namely, that no-one is wronged if Can Save One is true? An attractive aspect of Elizabeth Anscombe's defence of Can Save One is that she noted, in the case of Foot's original example of distributing the drug, that in such a case none of the five had a reasonable complaint if the drug was given entirely to the one. They had no grounds for complaint as none of them had been wronged. (Anscombe 1967)

But in my account it seems that the five have suffered a wrong. They have had a claim in non-comparative justice denied. So I need to say more about the distinction between having a claim in non-comparative justice denied and being treated unjustly and why the former is not "wronging" in an appropriate sense whereas the latter would be. In a Taurek case a rescuer acknowledges, and does not neglect, the non-comparatively just claim of each to be saved, though she also acknowledges that in the situation not all can be saved. She thereby acknowledges that some non-comparatively just claim(s) to be saved cannot be acted upon,

\footnotetext{
${ }^{24}$ More precisely, "I am not entirely convinced that these are the wrong lessons simply because the view that you can save the few in Many/Few strikes me, like almost everyone else, as lunatic". (Doggett forthcoming) ${ }^{25}$ More precisely, Can Save One, combined with the revision of Must Save Many as Can Save Many, where that latter principle articulates the moral relevance of the claims of each of the five in the group (so we end up with moral indifference again).
} 
although they are acknowledged rather than dismissed. In a Taurek case not all noncomparative claims to be saved can, and so shall, be 'met' in the sense of acted upon. ${ }^{26}$

The distinction I want to draw is between the fact that we acknowledge the claim in noncomparative justice of each of the five whom we do not save and the fact that we do not act to satisfy those claims. However, by saving the one and not the five, we do not act unjustly towards any of the latter. Not every failure to act so as to meet claims in non-comparative justice is an injustice. We might say that, in this case, life has been unjust, but that is a separate matter and, indeed, merely a figure of speech The only action in the situation is the act to save the one and by that act no one acts unjustly towards the five. So they have no reasonable complaint against the agent. Anscombe's point is that reasonable complaints require a proper object, namely, a person who has acted unjustly. Applying that thought to a Taurek style example allows re-phrasing in this way this way: one can regret that all of us are in this situation, but a generalized regret with no person at fault as its object is not a complaint ${ }^{27}$ (The rescuer can regret not being able to do more than she did, but this is not to concede that she was in any way at fault.)

Véronique Munoz-Dardé puts a similar point very helpfully in the course of her discussion:

I may have a duty to save, but not a duty to save you. A duty to save can be justified to each of the individuals involved even if not every single one of these individuals is going to be saved. The fact that I justify a principle to you does not by itself commit me to doing something for you. So our precise question is whether such a justification of a duty to (saving the greater number) can be offered to all individuals involved. (Munoz-Dardé 2005, p.211)

She is concerned here to assimilate Anscombe's objection to Foot's example into a more generally contractualist framework, but it is not a distinctively contractualist thought to note that a reasonable complaint needs a proper object. This point remains helpful even if one does not constitutively tie wrongs to wrongings in the way that the contractualist does for that narrow part of morality that concerns "what we owe to each other". The five who are not saved can truly say that they have suffered a wrong, but they are not victims of wrongdoing by anyone. So my view keeps the contractualist looking requirement that the reasons generated by a principle have to be given to each of the six candidates to be saved; however, I draw a non-contractualist distinction between wrongs and being wronged.

Anscombe claimed that, in Foot's example, were one to be saved, then none of the five would have been wronged. This can now be made more precise: each of the five has had their claim in non-comparative justice acknowledged, but not met. But that does not constitute being unjustly treated (so no-one is wronged in this sense) ${ }^{28}$ Failure to meet a claim in noncomparative justice is not unjust treatment because this omission did not involve any of the three canonical forms of non-comparative injustice, namely, discrimination, exploitation, or being subject to derogatory judgement. So none of the five has a reasonable complaint on any of

\footnotetext{
${ }^{26} \mathrm{I}$ am grateful to Ken Westphal for discussion of how this point is best formulated.

${ }^{27}$ Ken Westphal suggested to me a connection between the idea that a rescuer who fails to save someone from among several victims is somehow at fault and blameworthy and Nietzsche's account of the "morality of revenge". I think that is very insightful, but a consideration of that connection would go beyond the scope of the current discussion.

${ }^{28}$ I think this point suggests further compatibility between the argument here and that of Anscombe as she does not address the question of whether, if no one is wronged, any wrong has been committed. She asks, rather, "If no one was wronged, what injury did I do?" (Anscombe 1967, p. 17, emphasis added) where the phrase I have italicized brings out the dimension of agency. It is consistent with her silence on this point that the absence of a wronging is compatible with the presence of a wrong. That is why I think it is overreaching to recruit her as a contractualist.
} 
these three grounds. Everyone's claim has been acknowledged: it is the unfortunate contingencies of the situation which entail that not every claim has been met (because not every such claim could be met) although no agent has acted unjustly in saving the one and not the five. An agent would have to be held to account for acting unjustly and no one acts unjustly in saving the one and not the five.

The contingencies of the situation, recall, involve at least one person having a claim in justice acknowledged but not met, either the one, or a member of the group. No special reason to be saved accrues to one of the group solely "qua group member" because this "group' is no proper or relevant class. While all six people involved have a claim based on non-comparative justice only the one would be unjustly treated if the group were saved on the basis of Must Save Many; conversely, the group would not be discriminated against if the one were saved. I have already noted, in connection with the individualist lottery proposal, that this kind of discrimination is objectionable to Taurek's opponents. They are committed to the view that you must save many and, if you save a group, you have to save all the members of that group. That latter claim is based on the injustice of discrimination. They ought, therefore, to accept the reason that not saving the one solely because she is not in a group is discriminatory and therefore wrong.

None of the foregoing commits me to the obviously incorrect principle Must Save One. I have identified a class of evidential considerations that explain the distinctive wrongness of not saving the one solely because she is not in a group, but, qua particularist, I have more slack between identifying an evidential consideration and the determination of verdicts than my generalist opponents. So it is perfectly consistent for me to maintain Taurek's moral indifference claim, a thesis about overall verdicts, with the claim that there is a distinctive form of wrongness in not saving the one just because she is a singleton. That is an evidential consideration, but one that would suffice to ground a reasonable agent regret if the claim of the one is actually not met. ${ }^{29}$

\section{Numbers and Disasters}

This allows me to respond to another concern: on my view do the numbers never count? That conclusion also does not follow. Suppose that I am balancing the claims of the one and the many, yet "the many" is expanded, one by one, until it is a very large number. My choice is between saving the one, or saving a million. (Or, in the case of John T. Sanders's paper, ten billion.) (Sanders 1988) Does it follow that in this case, where the numbers are very large, Can Save One still generates a pertinent reason?

I believe that it does, but I can also see that in that very large number case the further principle Can Save Many is more likely to prove decisive in generating the overall verdict.

\footnotetext{
${ }^{29}$ This is the main point of difference between my view and that of Veronique Munoz-Dardé. (Munoz-Dardé 2005) She argues very insightfully that we have no reason to take Must Save Many uniquely to support a verdictive conclusion on the grounds that it is the only principle in play in a Taurek case. (See for example her crucial discussion of Anscombe at pp. 216-222 and especially page 220.) But because she does not appeal to the distinction between comparative and non-comparative justice she is not a position to identify the particular kind of wrong done to the one were this to be the only principle applicable to Taurek cases. Relatedly, MunozDardé offers no positive presumptive reason for the truth of Can Save One. In her overall position it remains in play by default on the general Anscombian ground of "the human need to be saved", whereas I further specify this reason as grounded in non-comparative justice. Munoz-Dardé concludes simply that "there may be further reasons an agent has that make intelligible his or her choice in saving one of the parties". (Ibid., p. 222) My aim here is to say a bit more than this, in a specific way that illustrates one form of Anscombe's general distinction between "a wrong committed without anyone being wronged". (Ibid., p. 219) But, clearly, this is not inconsistent with Munoz-Dardé's overall conclusion and I am indebted to her very fine discussion.
} 
However, I do not take this to be any concession to my opponent. It is perfectly open to a view of the kind that I have defended here to permit catastrophe clauses without undermining my basic argument. To think otherwise is to be committed to faulty "Sorites-style" reasoning characteristic of the reasons atomism that runs throughout criticism of Taurek. The critic of catastrophe clauses objects that as there is no known decisive point at which the numbers trigger the catastrophe clause it is irrational for a cardinal addition to the group to count for more as it approaches the "threshold" than it does after the triggering point has been reached. But this objection depends on a faulty, Sorites-style, pattern of reasoning that we know leads to a paradoxical conclusion. The view defended here is no more vulnerable to these problems than any other view. I concede that the method of pairwise comparison with its focus on case by case comparison seems to incorporate Sorites reasoning, but it is no major departure from the method to build in thresholds that trigger a different overall verdict across putatively similar cases. John Broome has, indeed, developed such a "threshold reason" view of this kind for Taurek cases, but within his framework of comparative justice. (Broome 1990; 2002))

Indeed, I am not only untroubled by the accusation that invoking catastrophe clauses is irrational; I also agree with Veronique Munoz-Dardé that it is the anti-Taurekian who has a problem with large numbers and not those sympathetic to Taurek's view:

This, however, just raises the puzzle for us of why you have so to inflate numbers to make the case obvious. For remember: the initial case was so framed that the only salient difference between the options was the number of people involved on each side. We might then wonder whether an alternative explanation is available of why the case introducing such a large differential is so compelling. (Munoz-Dardé 2005, p. 225)

I think that is exactly right. It is Taurek's critics who have to treat the case of one life versus five lives in exactly the same way as one life versus five billion lives. Munoz-Dardé draws attention to the fact that we have an independent intuition that very large numbers make a difference. There is independent moral force to avoiding what Nozick calls "catastrophic moral horror", as opposed to saving five versus saving the one. (Nozick 1974, p. 30) However it is Taurek's opponent who lacks the means of explaining why we have an independent issue here. That is because on her view the case of one versus five is not relevantly different to the case of one versus five billion, except via cardinal addition, one person at a time. (That is because of the underlying reasons atomism.) By contrast those sympathetic to Taurek, such as Munoz-Dardé and myself, can recognize that there is a distinct issue here. I elect to explain it by invoking the idea of threshold constraints and a catastrophe clause, but that is consistent with Taurek's basic argument, not a rejection of it.

For that reason, the view that I have defended here is at least consistent with the mixed solutions to Taurek cases defended by John T. Sanders, Veronique Munoz-Dardé, Rob Lawlor and Martin Peterson. Each in their different way wants to defend the view that the numbers sometimes count. But from my perspective any such view has to acknowledge that, if a threshold constraint or a catastrophe clause is invoked in a particular case to justify an overall practical verdict, that sacrifices the claim of the one to the claim of the many in a way that involves wrong doing. The one has, indeed, been sacrificed and the reason not acted upon grounds a reasonable agent regret that we could not have done otherwise. ${ }^{30}$

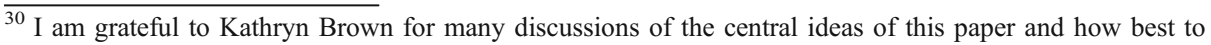
formulate them. Thanks also to Tom Bates, Mandy Bosma, David Janssens, Brad Hooker, Pauline Kleingeld, Gerald Lang, Mike Otsuka, Ben Saunders, Ken Westphal, Han van Wietmarschen, Bruno Verbeek, and, in particular, Tyler Doggett. Tyler took the trouble to send me many thoughtful comments on this paper that have greatly improved the end result.
} 
Open Access This article is distributed under the terms of the Creative Commons Attribution License which permits any use, distribution, and reproduction in any medium, provided the original author(s) and the source are credited.

\section{References}

Anderson E (1999) What is the point of equality? Ethics 109(2):287-337

Anscombe GEM (1967) Who is wronged? Oxford Review 5:16-17

Broome J (1990) Fairness. Proc Aristot Soc 91:87-102

Broome J (1998) Kamm on fairness. Philos Phenomenol Res 58(4):955-961

Broome J (2002) 'All goods are relevant'. In: Murray CJL, Salomon JA, Mathers CD, Lopez AD (eds) Summary measures of population health: concepts, ethics, measurement and applications. World Health Organization

Cohen GA (2008) Rescuing justice and equality. Harvard University Press, Cambridge

Dancy J (2004) Ethics without principles. Oxford University Press, Oxford

Doggett T (2009) What is wrong with Kamm's and Scanlon's arguments against Taurek? Journal of Ethics and Social Philosophy 3/3.

Doggett T (forthcoming) Saving the Few. Nous

Feinberg J (1974) Noncomparative justice. Philosophical Review 83(3):297-338

Foot P (1967) Abortion and the doctrine of double effect. Oxford Review 5:5-15

Kamm FM (1993) Morality, mortality, vol. 1. Oxford University Press, New York

Kamm FM (2007) Intricate Ethics. Oxford University Press, New York

Kumar R (2001) Contractualism on saving the many. Analysis 6:165-170

Lang G (2005) Fairness in life and death cases. Erkenntnis 62(3):321-351

Lawlor R (2006) Taurek, numbers and probabilities. Ethical Theory and Moral Practice 9(2):149-166

Lübbe W (2008) Taurek's no worse claim. Philosophy and Public Affairs. 36/1: 69-85

Munoz-Dardé V (2005) The distribution of numbers and the comprehensiveness of reasons. Proc Aristot Soc 105:207-233

Nozick R (1974) Anarchy, State and Utopia. Basic Books, New York

Otsuka M (2000) Scanlon and the claims of the many versus the one. Analysis 60:288-293

Peterson M (2010) Some versions of the number problem have no solution. Ethical Theory and Moral Practice 13(4):439-451

Sanders JT (1988) Why the numbers should sometimes count. Philosophy and Public Affairs 17(1):3-14

Scanlon TM (1999) What we owe to each other. Harvard University Press, Cambridge

Taurek J (1977) Should the numbers count? Philosophy and Public Affairs 6(4):293-316

Timmerman J (2004) The individualist lottery: how people count, but not their numbers. Analysis 64:106-112 